\title{
Electric Aircraft: Exploiting the Synergy between Powertrain, Energy Management and Structure
}

\author{
Teresa Donateo $^{1 *}$, Claudia Lucia De Pascalis ${ }^{1}$, Antonio Ficarella ${ }^{1}$ \\ ${ }^{1}$ Dept. of Engineering for Innovation, University of Salento, Lecce, Italy
}

\begin{abstract}
This study aims at investigating the synergy between powertrain and structure within the design process of a fixed-wing tailsitter unmanned aerial vehicle (UAV). The UAV is equipped with a pureelectric power system and has vertical take-off and landing capabilities (VTOL). The problem is addressed by running a contemporary optimization of the parameters of both the powertrain and the UAV's structure, in order to maximize electric endurance and payload weight through the usage of a performant multi-objective evolutionary algorithm named SMS-EMOA. Three different designs are selected, discussed and compared with literature results on the same UAV to quantify the increase of payload and cruise time that can be obtained by exploiting the synergy between structure and powertrain. The potentiality of furtherly improving payload through the usage of multi-functional panels, while keeping the same endurance, is also quantified and compared with the technologies proposed in literature.
\end{abstract}

\section{Introduction}

The superior energy density of hydrocarbon fuels makes them a favourite technology for aircraft propulsion and mobility in general. However, an ever-increasing interest in the electric systems is encouraged by the remarkable benefits of this technology, such as high power-to-weight ratio, efficiency, reliability, compactness, quietness, and, above all, elimination of local pollutant emissions.

Electrification began to take part in the aerospace industry firstly with the More Electric Aircraft (MEA) concept. Then, electric powertrains have been introduced for propulsive purposes too, with hybrid-electric propulsion systems as mid-term solution to improve the overall fuel economy and reduce environmental impact. However, technical barriers prevent full-electric propulsion systems to reach values of energy storage density (and therefore endurance) comparable with hydrocarbon fuels. For this reason, pure-electric propulsion is still unconceivable for large aircraft, such as commercial planes, unless new technologies are developed for batteries. On the contrary, it is more and more frequently used as the aerial vehicle size decreases [1], such as for small Unmanned Aerial Vehicles (UAVs).

\footnotetext{
*Corresponding author: teresa.donateo@unisalento.it
} 
However, new technologies like the multi-functionalization of composite materials may leads to further benefits resulting from the synergy between structure and propulsion. This study addresses the potentiality of exploiting such synergy by performing the contemporary optimization of structure and all-electric powertrain for a UAV with vertical take-off and landing (VTOL). In particular, this investigation takes inspiration from the study of Aksugur et al. [2] that proposes a pure-electric propeller-ducted fan propulsion system to be used as powertrain on a tail-sitter UAV. This system employs a folding propeller for the low speed-high power flight phases and an electric ducted fan (EDF) for the level-high speed flight mode, when propeller folds onto the fuselage. For designing such a UAV, Aksugur et al. [2] selected a propulsion system a priori and then realized the UAV design by optimizing four aircraft design parameters. In this investigation, we considered the same UAV, with the same kind of all-electric hybrid propulsion system, but performed optimization of the propulsive units together with the aircraft architecture. See Table 1 for a comparison of the design parameters of this study and Aksugur et al. [2].

Table 1. Optimization problems design parameters

\begin{tabular}{|c|c|c|}
\hline Design parameters & $\begin{array}{c}\text { Aksugur et al., 2011 } \\
\text { [2] }\end{array}$ & This study \\
\hline Wing span $(\mathrm{b})$ & $\mathrm{V}$ & $\mathrm{V}$ \\
\hline Wing loading $\left(W_{0} / S\right)$ & $\mathrm{V}$ & $\mathrm{V}$ \\
\hline Horizontal tail arm $\left(l_{H T}\right)$ & $\mathrm{V}$ & $\mathrm{V}$ \\
\hline Take-off weight $\left(W_{0}\right)$ & $\mathrm{V}$ & $\mathrm{V}$ \\
\hline $\begin{array}{c}\text { PROPELLER: diameter }\left(D_{p}\right) \text {, blade angle }\left(\varphi_{p}\right) \text { and } \\
\text { number of blades }\left(n_{p}\right)\end{array}$ & $\mathrm{X}$ & $\mathrm{V}$ \\
\hline $\begin{array}{c}\text { MOTOR: maximum voltage }\left(U_{m M a x}\right), \text { maximum } \\
\text { current }\left(I_{m M a x}\right) \text {, and } \mathrm{KV} \text { value }\left(K_{v}\right)\end{array}$ & $\mathrm{X}$ & $\mathrm{V}$ \\
\hline $\begin{array}{c}\text { BATTERY: maximum discharge rate }\left(K_{b}\right) \text { and } \\
\text { capacity }\left(C_{b}\right)\end{array}$ & $\mathrm{X}$ & $\mathrm{V}$ \\
\hline EDF: fan diameter $\left(D_{f}\right)$ and rounds per minute $\left(n_{E D F}\right)$ & & \\
\hline
\end{tabular}

Another novelty of this investigation is the usage of an advanced optimization algorithm, SMS-EMOA [3], instead of the MOGA-II used in the study of Aksugur [2]. The choice of this innovative algorithm was motived from a parallel study that showed how SMS-EMOA performs better than MOGA-II in this kind of application (constrained biobjective problem) [4]. Finally, the further advantage of structural integration and multifunctionalization is also addressed through a scouting of the battery integration technologies proposed in literature.

\section{Structural integration and multi-functionalization}

Structural integration means embedding a part into the primary structure of the overall system and making the latter fulfil some structural tasks (such as carrying loads and shape retention) in order to save weight and volume. A step ahead of structural integration is the multi-functionalization that consists of designing system components to perform multiple (at least two) predetermined functions. An interesting example is the multifunctionalization of fiber-reinforced composite materials (see Fig. 1a) to add electrical energy storage capabilities [3]. This allows an increasing of energy density, with respect to the conventional energy storage systems, because part of the battery mass can be included in the aircraft structure. Therefore, multifunctional composites can be very interesting in the design of electrified airplanes. Note that, structural properties and failure modes of the modified material should be investigates, as well as the storage ability of the 
multifunctional component as a function of shapes, materials, loads and strains. However, this is beyond the scope of this investigation.

If the structural parts get energy storage tasks and the battery contributes to the structural functions, it is possible to quantify the mass saving potentiality with the following equation:

$$
m_{\text {total }}=m_{\text {structure }}+\left(1-\sigma_{s}^{\text {battery }}\right) \cdot\left(m_{\text {battery }} / \sigma_{e}^{\text {battery }}\right)
$$

In Eq. (1), $m_{\text {total }}$ is the total mass of the system, $m_{\text {structure }}$ is the mass of the system structure and $m_{\text {battery }}$ is the conventional battery mass, while $\sigma_{s}$ represents structural properties (e.g. stiffness or strength) and $\sigma_{e}$ measures the energy mass efficiency.

In the conventional case (functional separation and no-integration), $\sigma_{s}^{\text {battery }}=$ $\sigma_{e}^{\text {structure }}=0$, and $\sigma_{e}^{\text {battery }}=\sigma_{s}^{\text {structure }}=1$.

Fig. 1b [3] illustrates the mass correlation of Eq. (1) for a sample system having $m_{\text {structure }}=2000 \mathrm{~kg}$ and $m_{\text {battery }}=750 \mathrm{~kg}$. In the conventional case, $m_{\text {total }}=$ $2750 \mathrm{~kg}$. The total mass is reduced to $2500 \mathrm{~kg}$ if $\sigma_{e}^{\text {battery }}=0.8$ and $\sigma_{s}^{\text {battery }}=0.47$ or $\sigma_{e}^{\text {battery }}=0.5$ and $\sigma_{s}^{\text {battery }}=0.67$.

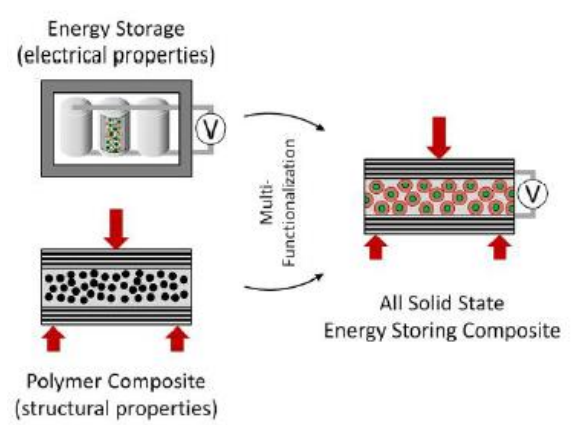

(a)

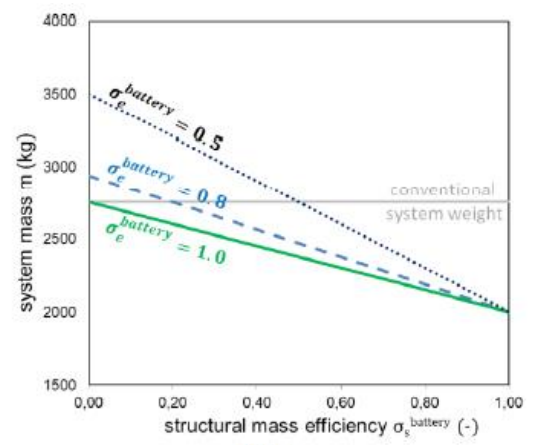

(b)

Fig. 1. Concept of multifunctional energy storing composite materials [3]

\section{Modelling the power system}

The VTOL-UAV considered in this study is powered by an all-electric system. The electric folding propeller is installed on the nose of the aircraft and used for vertical take-off and landing, hovering and low-speed transition mode phases. The EDF unit is placed between the aircraft tail surfaces for providing power during cruise. Both propulsion units consist of a battery, an electronic speed control (ESC), a motor (see Fig. 2).

The white arrows of Fig. 2 show the energy flows throughout the system, while the orange arrows illustrate the backward approach used for the modelling. In this approach, the required thrust of each propulsion unit is the input of the model while the current and voltage of the two batteries are the outputs. The parameters of each component of the power system are adjusted in order to satisfy the power demand and the efficiency of each element is taken into account. For propeller, motor, ESC and battery, the models proposed from Shi et al. [4] are implemented. The propeller model takes the required thrust and the propeller design variables of Table 4 as input parameters and calculates torque, rounds-perminute, and weight. The BLDC-Motor model uses as input parameters the design variables of Table 4 together with the corresponding propulsion unit (propeller or EDF) rounds-perminute and torque, and outputs the motor current, voltage, and weight. The ESC model calculates the weight, after having received the motor voltage and current as inputs, and set 
the ESC maximum and effective current and voltage equal to those of the BLDC-Motor. The battery model takes as inputs the motor actual current and maximum voltage, and the corresponding design variables of Table 4 , and outputs the battery weight and dischargetime. [6].

The battery discharge time is estimated by using the formula proposed by Donateo et al.

$$
\mathrm{t}_{\mathrm{d}, \mathrm{T}}=\left(\frac{\mathrm{I}_{\mathrm{nom}}}{\mathrm{C}}\right)^{1-\mathrm{n}}\left(\frac{\mathrm{n}_{\mathrm{s}} \mathrm{V}_{\text {cell }} \mathrm{C}}{\mathrm{P}_{\text {batt }}} \cdot \frac{\mathrm{DOD}}{100}\right)^{\mathrm{n}}
$$

In Eq. (2), $I_{n o m}$ is the nominal current of the battery, $C$ is the battery capacity, $n_{s}$ is the number of battery cells in series, $V_{\text {cell }}$ is the voltage of the single battery cell, $\mathrm{P}_{\text {batt }}$ is the battery delivered power, and $n$ is the Peukert's coefficient equal to 1.05. Note that this is the same formula proposed by Traub [1] but corrected with the Depth of Discharge (DOD) of the battery ( $80 \%$ for lithium-polymer batteries) and validated through comparison with experimental data in Donateo et al. [6].

For the UAV empty weight calculation, the same mathematical model of Aksugur et al. [2] is considered, which takes as inputs the first four design variables of Table 4 and delivers the UAV empty weight.

Finally, the EDF unit model implements formulas suggested in reference [5] and its weight is statistically determined as a function of the fan diameter. In particular, the EDF model takes as input parameter the required thrust and the corresponding design variables of Table 4, returning the EDF's shaft round-per-minute and torque.

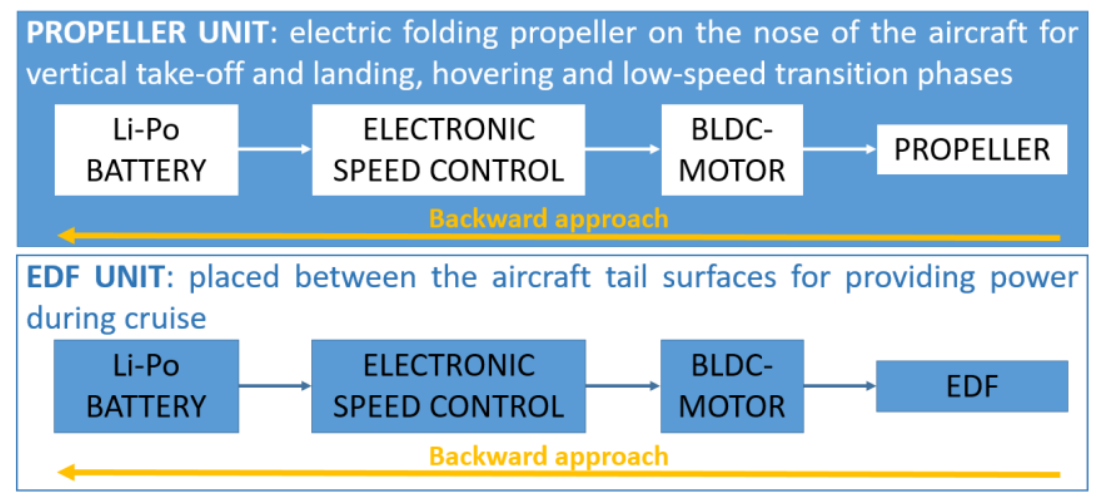

Fig. 2. Electric power system workflow

\section{Optimization problem and tools}

The optimization problem is run by considering the design points of Table 2, the requirements of Table 3, and the design variables bounds of Table 4. Further constraints are included in order to ensure the results to be physically sensible. Technical limitations in terms of tip speed of blades, and voltage, current and torque of electrical devices are also taken into account.

The optimization tool used for this problem is the evolutionary algorithm SMS-EMOA (S-Metric Sorting Evolutionary Multi-Objective Algorithm) [7]. This algorithm belongs to the class of evolutionary algorithms that are robust and powerful search mechanism for single and multi-objective optimizations, extensively used in many engineering applications. SMS-EMOA turned out to be the best method for this application (constrained bi-objective problem) among those analysed by authors in other studies [8]. It is characterized by constant population size, a dominance-based sorting criterion and an 
hypervolume-based ranking criterion. The original version of SMS-EMOA [9] was modified by the authors of the present investigation in order to include constraints handling.

Table 2. Design point for Propeller and EDF units

\begin{tabular}{|c|c|}
\hline Propeller unit & 3 minutes at hover mode at $1 \mathrm{~km}$ of altitude \\
\hline EDF unit & Cruise at $\mathrm{V}_{\text {cruise }}=50 \mathrm{~m} / \mathrm{s}$ at $1 \mathrm{~km}$ of altitude \\
\hline
\end{tabular}

Table 3. Design requirements and constraints for the optimization problem

\begin{tabular}{|c|c|}
\hline & $\mathrm{V}_{\text {stall }} \leq 30 \mathrm{~m} / \mathrm{s}$ \\
Operation Capability & $\mathrm{V}_{\text {cruise }} \leq 50 \mathrm{~m} / \mathrm{s}$ \\
& $\mathrm{V}_{\text {cruise }}-\mathrm{V}_{\text {stall }} \geq 3 \mathrm{~m} / \mathrm{s}$ \\
& Range $\leq 20 \mathrm{~km}$ \\
\hline Design requirements & $\mathrm{t}_{\text {cruise }} \geq 30 \mathrm{~min}, \mathrm{~W}_{\text {pay }} \geq 0.8 \mathrm{~kg}$ \\
\hline Geometrical limits & $\mathrm{AR} \geq 4, \mathrm{l}_{\text {fuselage }} \leq \mathrm{b}$ \\
\hline
\end{tabular}

Table 4. Design variables bounds for the optimization

\begin{tabular}{|c|c|c|}
\hline Design variable & Lower bound & Upper bound \\
\hline Wing span $(\mathrm{b})$ & $1 \mathrm{~m}$ & $2 \mathrm{~m}$ \\
\hline Wing loading $\left(W_{0} / S\right)$ & $100 \mathrm{~N} / \mathrm{m}^{2}$ & $220 \mathrm{~N} / \mathrm{m}^{2}$ \\
\hline Horizontal tail arm $\left(l_{H T}\right)$ & $0.6 \mathrm{~m}$ & $1.5 \mathrm{~m}$ \\
\hline UAV weight $\left(W_{0}\right)$ & $30 \mathrm{~N}$ & $100 \mathrm{~N}$ \\
\hline Propeller diameter $\left(D_{p}\right)$ & $0.5 \mathrm{~m}$ & $1.2 \mathrm{~m}$ \\
\hline Propeller blade angle $\left(\varphi_{p}\right)$ & $3 \mathrm{deg}$ & $30 \mathrm{deg}$ \\
\hline EDF fan diameter $\left(D_{f}\right)$ & $0.07 \mathrm{~m}$ & $0.16 \mathrm{~m}$ \\
\hline EDF rounds per minute $\left(n_{E D F}\right)$ & $20^{\circ} 000 \mathrm{rpm}$ & $50^{\circ} 000 \mathrm{rpm}$ \\
\hline $\begin{array}{c}\text { Propeller/EDF motor maximum voltage } \\
\left(U_{m M a x}\right)\end{array}$ & $6 \mathrm{~V} / 6 \mathrm{~V}$ & $24 \mathrm{~V} / 78 \mathrm{~V}$ \\
\hline $\begin{array}{c}\text { Propeller/EDF motor maximum current } \\
\left(I_{m M a x}\right)\end{array}$ & $20 \mathrm{~A} / 5 \mathrm{~A}$ & $180 \mathrm{~A} / 180 \mathrm{~A}$ \\
\hline Propeller/EDF motor KV value $\left(K_{v}\right)$ & $60 \mathrm{rpm} / \mathrm{V} / 1200 \mathrm{rpm} / \mathrm{V}$ & $360 \mathrm{rpm} / \mathrm{V} / 2100 \mathrm{rpm} / \mathrm{V}$ \\
\hline $\begin{array}{c}\text { Propeller and EDF batteries maximum } \\
\text { discharge rate }\left(K_{b}\right)\end{array}$ & $10 \mathrm{C}$ & $95 \mathrm{C}$ \\
\hline Propeller/EDF battery capacity $\left(C_{b}\right)$ & $5 \mathrm{Ah} / 5 \mathrm{Ah}$ & $22 \mathrm{Ah} / 60 \mathrm{Ah}$ \\
\hline
\end{tabular}

\section{Results and discussion}

The results of the optimization are shown in Fig. 3and compared to those from the study of Aksugur et al. [2]. In particular, the blue line and the blue circle represent, respectively, the Pareto optimal front and the final design in Aksugur et al. [2], while the black points are the results of the optimization problem worked out in this study. These results show the importance of the introduction of the power system parameters into the aircraft design optimization. In particular, it is found that thanks to the synergy between aircraft design and powertrain, it is possible to obtain enhancements in the target performances (higher payload weight and cruise time). For example, it is possible to obtain the same payload of point blue $(1 \mathrm{~kg})$ with a double cruise time (from about 120 to about $230 \mathrm{~min}$ ).

Finally, the yellow, red, and green points represent the final designs selected by authors of this paper among the optimal solutions found out by SMS-EMOA. They are, respectively, the solutions of maximum payload, maximum cruise time and best trade-off. The final choice between the optimal solutions depends on the relative importance of the two goals and is left to the final decision maker. 
Table 5 shows the design parameters corresponding to the selected solutions. Note that, in all cases the optimal designs of this investigation are characterized by a lower weight and a shorter wingspan than that of Aksugur et al. [2].

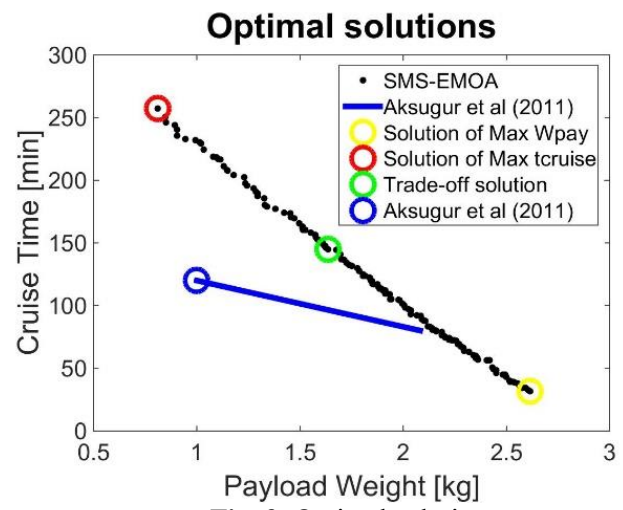

Fig. 3. Optimal solutions

Table 5. Design variables of the three optimal design points

\begin{tabular}{|c|c|c|c|c|c|c|}
\hline Design point & b $[\mathbf{m}]$ & $l_{H T}[\mathrm{~m}]$ & $W_{0} / S\left[\mathrm{~N} / \mathrm{m}^{2}\right]$ & $W_{0}[\mathrm{~N}]$ & $D_{p}[\mathbf{m}]$ & $\varphi_{p}[\mathrm{deg}]$ \\
\hline Sol a) & 1.210 & 0.684 & 220 & 72.0 & 0.815 & 28.0 \\
\hline Sol b) & 1.210 & 0.697 & 220 & 71.0 & 0.824 & 29.7 \\
\hline \multirow[t]{2}{*}{ Sol c) } & 1.212 & 0.692 & 220 & 71.2 & 0.824 & 29.6 \\
\hline & $\begin{array}{c}U_{\text {mMax }}[\mathrm{V}] \\
\text { Propeller }\end{array}$ & $\begin{array}{l}I_{\text {mMax }}[\mathrm{A}] \\
\text { propeller }\end{array}$ & $\begin{array}{c}K_{v}[\mathrm{rpm} / \mathrm{V}] \\
\text { propeller }\end{array}$ & $\underset{\mathrm{EDF}}{U_{\text {mMax }}[\mathrm{V}]}$ & $\underset{\text { EDF }}{I_{\text {max }}[\mathbf{A}]}$ & $\begin{array}{c}K_{v}[\mathrm{rpm} / \mathrm{V}] \\
\text { EDF }\end{array}$ \\
\hline Sol a) & 15.3 & 125.5 & 79.7 & 18.8 & 8.58 & $\sim 1753$ \\
\hline Sol b) & 15.3 & 125.0 & 75.4 & 18.9 & 8.75 & $\sim 1641$ \\
\hline \multirow[t]{2}{*}{ Sol c) } & 15.3 & 125.0 & 76.2 & 18.9 & 8.75 & $\sim 1633$ \\
\hline & $\begin{array}{c}K_{b}[C] \\
\text { Propeller }\end{array}$ & $\begin{array}{l}C_{b}[\mathrm{mAh}] \\
\text { Propeller }\end{array}$ & $\begin{array}{c}K_{b}[C] \\
\text { EDF }\end{array}$ & $\begin{array}{c}C_{b}[\mathrm{mAh}] \\
\mathrm{EDF}\end{array}$ & $n_{f}[\mathbf{r p m}]$ & $D_{f}[\mathrm{~m}]$ \\
\hline Sol a) & 18.63 & 9979.62 & 10.0 & 5680.0 & $\sim 31244$ & 0.100 \\
\hline Sol b) & 57.96 & 9931.97 & 10.2 & 28758.6 & $\sim 30426$ & 0.119 \\
\hline \multirow[t]{2}{*}{ Sol c) } & 57.03 & 10006.49 & 32.9 & 17513.7 & $\sim 30285$ & 0.116 \\
\hline & $n_{p}$ & & & & & \\
\hline Sol a), b), c) & 4 & & & & & \\
\hline
\end{tabular}

Further improvements could be obtained with the integration/multi-functionalization concept. Let's identify, with the help of Eq. 1, the values of $\sigma_{s}^{\text {battery }}$ and $\sigma_{e}^{\text {battery }}$ which, starting from solutions (b) and (c), could allow the same payload of solution (a). The results are shown in Fig. 4, where the total mass represents the aircraft empty weight in order to get a payload equal to $2.61 \mathrm{~kg}$, that is $4.64 \mathrm{~kg}$ and $4.65 \mathrm{~kg}$ for (b) and (c), respectively.

The couples of values that let to obtain this result are shown in Fig. 4a and are represented by the following couples: $\left(\sigma_{e}^{\text {battery }}=1, \sigma_{s}^{\text {battery }}=0.686\right) ;\left(\sigma_{e}^{\text {battery }}=0.8\right.$, $\left.\sigma_{s}^{\text {battery }}=0.749\right)$, and $\left(\sigma_{e}^{\text {battery }}=0.5, \sigma_{s}^{\text {battery }}=0.843\right)$.

By repeating the calculation for the trade-off solution (c) in order to obtain the same payload weight of the solution (a), the couples of values are $\left(\sigma_{e}^{\text {battery }}=1, \sigma_{s}^{\text {battery }}=\right.$ $0.536) ;\left(\sigma_{e}^{\text {battery }}=0.8, \sigma_{s}^{\text {battery }}=0.629\right)$, and $\left(\sigma_{e}^{\text {battery }}=0.5, \sigma_{s}^{\text {battery }}=0.768\right)$. In the latter case, the aircraft empty weight should be equal to $4.65 \mathrm{~kg}$. 
Note that the same result may be obtained with different combinations of the two parameters. In particular, it is possible to observe that $\sigma_{e}{ }^{\text {battery }}$ decreases as $\sigma_{s}^{\text {battery }}$ increases. Since it is desirable for the battery to maintain most of its energy efficiency while getting structural skills, a multi-objective optimization aiming at maximizing both the efficiencies might indicate sensible parameters to be focused on in order to obtain improvements in this field, by taking into account the multi-functionalization effects on both the energy and structural aspects into the system model.

a) For solution (b)

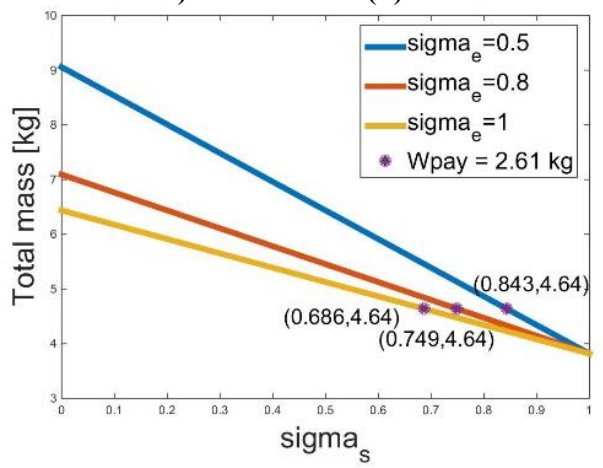

b) For solution (c)

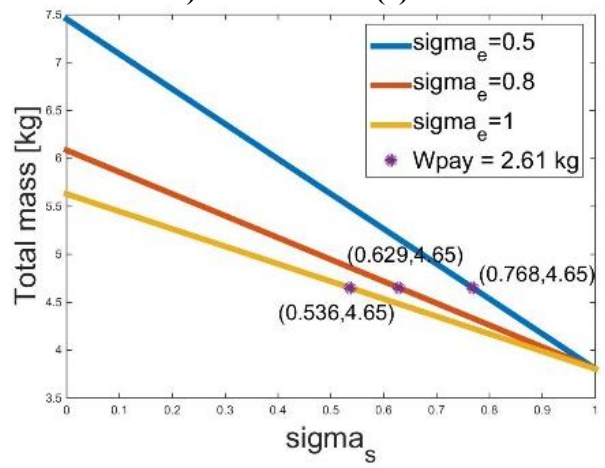

Fig. 4. System Masses for Various Structural Efficiencies $\left(\boldsymbol{\sigma}_{\boldsymbol{s}}\right)$ and Energy Densities $\left(\boldsymbol{\sigma}_{\boldsymbol{e}}\right)$

The next step was to verify if the technologies proposed in literature for multifunctional panels can reach these requirements. Reference [10] suggests various approaches for creating multi-functional energy storage devices and describes the development of structural batteries, capacitors, and supercapacitors. In addition, reference [3] provides various studies as examples of different degrees of integration and multi-functionalization. Among the proposed technologies, the storage device shown in Fig. 6 is the most suitable for the goals of this investigation. It considers carbon fibers as electrodes, glass-fiber mats as separators, and matrix material for the electrolyte [10].

From the results of [11] (see Fig. 5) and by using definitions of Eq.s (3) [11], it is possible to verify that this technologies satisfy the couples of values $\left(\sigma_{e}^{\text {battery }}=0.8\right.$, $\left.\sigma_{s}^{\text {battery }}=0.749\right)$ and $\left(\sigma_{e}^{\text {battery }}=1, \sigma_{s}^{\text {battery }}=0.536\right)$, that allow solutions $(b)$ and $(\mathrm{c})$ to obtain the same payload of solution (a).

$$
\sigma_{e}=\frac{\text { actual energy density }}{\text { reference energy density }} \quad \text { and } \quad \sigma_{s}=\frac{\text { actual structural property }}{\text { reference structural propertt }}
$$

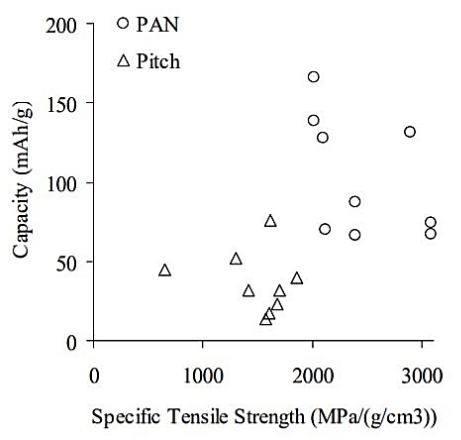

Fig. 5. Performances of multi-functional batteries with carbon-fibers anodes [11] 


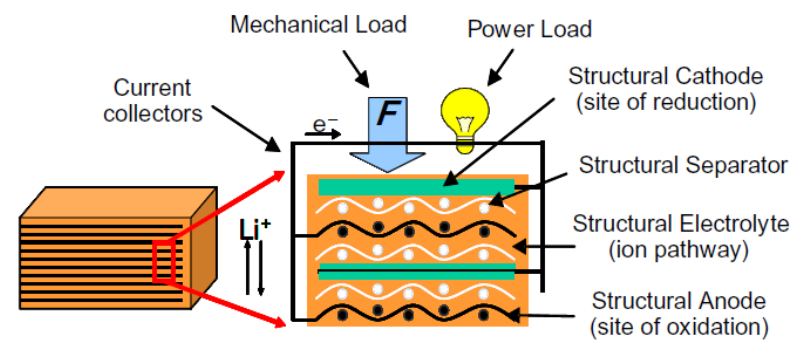

Fig. 6. Structural battery scheme [10]

\section{Conclusions}

This investigation describes the preliminary design of a fixed-wing tail-sitter VTOL UAV through the optimization of the powertrain components together with the main aircraft design specifications, in order to maximize the aircraft payload weight and cruise time. In particular, three different designs have been selected and discussed for the VTOL $\mathrm{UAV}$, and some technologies from literature are suggested as good starting point in order to obtain the benefits from the structural integration and multi-functionalization.

Results show that it is possible to obtain large improvements in terms of the target performances thanks to the synergy between aircraft design and powertrain, with respect to when the design processes for structure and power system are carried out separately. In particular, it was found that benefits up to $+25 \%$ may be obtained in terms of maximum payload, and up to $+112 \%$ in terms of maximum cruise time, by exploiting the synergy between aircraft structural and energy aspects

Further benefits in terms of weight might be reached by applying structural multifunctionalization technologies, such as by storing energy in the composite laminate by adding energy functions to its constituents. In this study it is found that existing technologies for multi-functionalization could allow the maximum endurance solution to carry the same weight of the maximum payload solution.

\section{References}

1. L. W. Traub, J Aircr, 48, No. 2: 703-707 (2011)

2. M. Aksugur, G. Inalhan, Ankara International Aerospace Conference (2011)

3. T. J. Adam, G. Liao, J. Petersen, S. Geier, B. Finke, P. Wierach, A. Kwade, M. Wiedemann, Energies, 11, 335 (2018)

4. D. Shi, X. Dai, X. Zhang, Q. Quan, IEEE ASME Trans Mechatron, 22, 1337-1348 (2017)

5. Y. Jiang, B. Zhang, T. Huang, Aerospace, 2, 555-580 (2015)

6. T. Donateo, L. Spedicato, Appl Energy, 206, $723-738$ (2017)

7. N. Beume, B. Naujoks, M. Emmerich, Eur J Oper Res, 181, 1653-1669 (2007)

8. T. Donateo, C. L. De Pascalis, A. Ficarella, Conference Proceeding of The Tenth International Conference on Engineering Computational Technology (2018)

9. https://github.com/numbbo/coco/blob/master/code-experiments/examples/bbob-biobjmatlab-smsemoa/SMSEMOA.m, accessed on 20 June, 2018

10. J. F. Snyder, D. J. O'Brien, E. D. Wetzel, Materials and Energy Handbook of Solid State Batteries, 657-699 (2015)

11. J. F. Snyder, R. H. Carter, K. Xu, E. I. Wong, P. A. Nguyen, E. H. Hgo, E. D. Wetzel, U.S. Army Research Laboratory, Report number : ARL-RP-193 (2007) 